\title{
Treatment of Multiple Dural Arteriovenous Fistulas Associated with Visual Disturbances in a Chronic Schizophrenia Patient: A Case Report
}

\author{
Yunsuk Choi, Jong Un Moon, Cheol Su Jwa \\ Department of Neurosurgery, National Medical Center, Seoul, Republic of Korea
}

Corresponding author:

Jong Un Moon

Department of Neurosurgery,

National Medical Center, 245

Eulji-ro, Jung-gu, Seoul 04564,

Republic of Korea

Tel: $+82-2-2260-7185$

Fax: $+82-2-2260-7482$

E-mail: nsdocmoon@gmail.com

Received: March 13, 2018

Revised: March 22, 2018

Accepted: March 29, 2018
A 51-year-old woman presented with visual disturbances that had persisted for approximately one year. She had been taking psychiatric medication for schizophrenia. Brain magnetic resonance imaging showed engorged vessels in both hemispheres, and a delay in the mean transit time and time to peak was observed on perfusion images. The initial transfemoral cerebral angiography showed multiple dural arteriovenous fistulas (AVFs) with cortical venous reflux and venous ectasia. Both middle meningeal arteries (MMAs), superficial temporal arteries (STAs), and occipital arteries (OAs) were feeding the fistulas, and the superior sagittal sinus was the draining vein. Owing to the presence of multiple lesions and feeder arteries, a staged treatment was planned. We first performed the Onyx embolization of the left MMA, followed by the surgical ligation of the left STA, with subsequent embolization of the left OA. Finally, the venous ectasia was clipped. Importantly, after treatment, the patient's schizophrenia-like symptoms improved. The patient could be originally misdiagnosed with schizophrenia. This case shows that staged and active treatment should be considered in case of multiple dural AVFs for improvement of symptoms.

Key Words: Arteriovenous fistula; Intracranial arteriovenous malformations; Schizophrenia

\section{INTRODUCTION}

Dural arteriovenous fistulas (AVFs) are abnormal direct continuations of arteries and veins within the dura. Dural AVFs account for approximately $10 \%$ to $15 \%$ of all intracranial arteriovenous malformations ${ }^{8,13}$. The common treatment modalities for dural AVFs include surgical resection, endovascular embolization, radiation therapy, and conservative clinical management.

Multiple dural AVFs are very rare and hard to treat; these cases account for $6 \%$ to $9 \%$ of all cases of dural AVFs ${ }^{1,5,15)}$. Patients with multiple dural AVFs have a high risk of hemorrhage, which includes venous obstruction ${ }^{1)}$, and aggressive treatment modalities are often required to improve neurological and cognitive symptoms in these patients ${ }^{4)}$.

The common initial symptoms of AVFs are headaches, tinnitus, proptosis, and intracranial hemorrhage ${ }^{3,8,14)}$. Several cases of dural AVFs accompanied by cognitive symptoms such as dementia, Parkinsonism, amnesia, and alexia have been reported $^{6,7,9-12,16,17)}$. However, to our knowledge, there have been no reports on schizophrenia as a presenting symptom of dural AVFs so far.

In this study, we report our experience with a patient presenting with multiple dural AVFs and schizophrenia-like symp- toms, who was treated using a staged and active treatment strategy.

\section{CASE REPORT}

A 51-year-old woman presented with visual disturbances that had persisted for approximately one year. She was under treatment with the following psychiatric medications: paliperidone (9 mg, QD), benztropine mesylate (2 mg, QD), lorazepam (1 mg, QD), quetiapine fumarate (100 mg, QD), trazodone hydrochloride (25 mg, QD), and propranolol hydrochloride (20 mg, BID); these drugs were being administered for the treatment of schizophrenia at a psychiatric hospital. The patient had been showing symptoms of delusion, negative symptoms, and dysphoric mania for an 11-year period. Brain magnetic resonance imaging (MRI) was performed at a previous hospital because the patient experienced visual disturbances. The initial MRI scans showed vasogenic cerebral edema in the left temporo-occipital area and engorged vessels in both cerebral hemispheres. The patient was then transferred to our research hospital for additional examinations. Subsequent MRI scans of the brain confirmed the presence of engorged vessels in both cerebral hemispheres and a delay in the mean transit 
time (MTT) and time to peak (TTP) on perfusion images (Fig. $1 \mathrm{~A}-\mathrm{C})$. We also performed transfemoral cerebral angiography (TFCA) examinations as we suspected the presence of dural AVFs. The TFCA revealed multiple dural AVFs, along with cortical reflux and venous ectasia. The feeding arteries identified were as follows: both middle meningeal arteries (MMAs), superficial temporal arteries (STAs), and occipital arteries (OAs). The superior sagittal sinus (SSS) was the draining vein. In the right internal carotid artery (ICA), early enhancement of the SSS and cortical vein drainage were observed, but no feeding artery was present. In the right external carotid artery (ECA), the fistula penetrated through the bone to the SSS from the right STA parietal branch. In the SSS, the fistula penetrated from the right MMA posterior branch, and through the bone from the right $\mathrm{OA}$. In the left ICA, there was an early enhancement of the SSS and cortical vein drainage, but no feeding artery was observed. In the left ECA, the fistula penetrated through the bone to the SSS from the left STA parietal branch and the fistula in the SSS from the left anterior and posterior MMA branches. The fistula penetrating through the bone from the left $\mathrm{OA}$ and venous ectasia were located around the transverse sigmoid sinus junction, and early enhancement of the SSS and cortical vein drainage were observed (Fig. 1D, F).

It appeared that the feeder arteries of the left ECA were the main feeder arteries of the AVFs, and we therefore planned a stepwise treatment. The feeder arteries included the left MMA, the left STA, the left OA, and the venous ectasia (Fig. 2A). In order to accomplish this, we first performed Onyx embolization of the left MMA. We then used the steerable vascular Rebar microcatheter for the left MMA anterior and posterior branches (Fig. 2B). Subsequently, we performed an ultrasound-guided surgical ligation of the left STA using the Doppler system under local anesthesia. Finally, we performed Onyx embolization of the left OA using a Marathon microcatheter platform (Fig, 2C), and we then clipped the venous ectasia using navigation system, under general anesthesia (Fig. 2D). Postoperative TFCA showed no fistula on the left STA, MMA, OA, or venous ectasia, and instead showed a marked decrease in cortical draining veins (Fig. 3A, B). Follow-up brain MRI performed 20 days after the surgery showed a prominent decrease in engorged vessels in both hemispheres, compared to the initial MRI scan (Fig. 3C).

After the surgery, the patient's schizophrenia symptoms were improved. Remarkably, although the patient stopped taking the schizophrenia medication that was initially prescribed, she could express her thoughts logically, could express her emotions precisely, and her delusions also disappeared.

\section{DISCUSSION}

As mentioned above, dural AVFs are associated with symptoms such as headaches, tinnitus, proptosis, and intracranial hemorr-
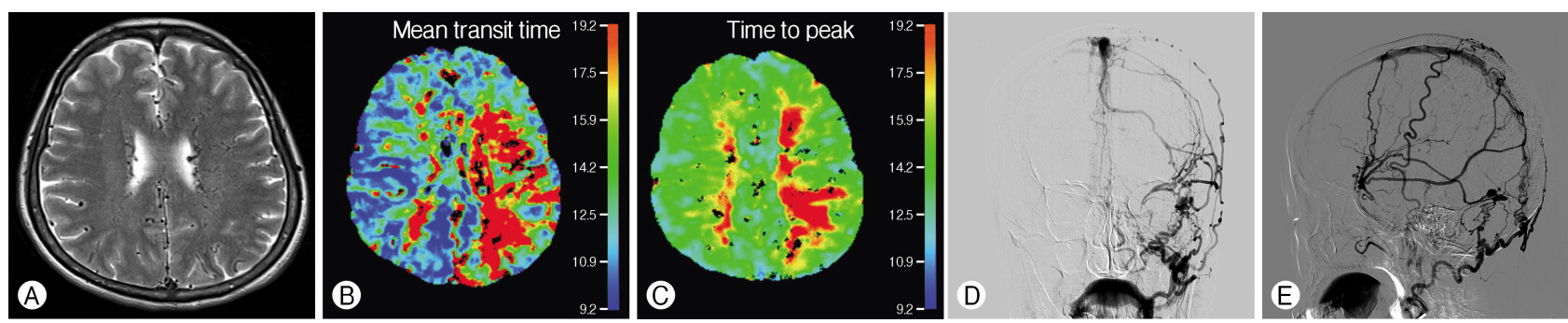

Fig. 1. (A) T2-weighted magnetic resonance image of the brain shows engorged vessels and vascular signal void in both hemispheres. (B) A delay in the mean transit time and (C) time to peak are observed. Initial transfemoral cerebral angiography shows that in the left external carotid artery, there are the fistula penetrating through the bone to superior sagittal sinus (SSS) from left superficial temporal artery parietal branch and the fistula to SSS from left middle meningeal arteries anterior and posterior branches and the fistula penetrating through the bone from left occipital artery and venous ectasia around the transverse sigmoid sinus junction. (D) Coronal view, (E) sagittal view.
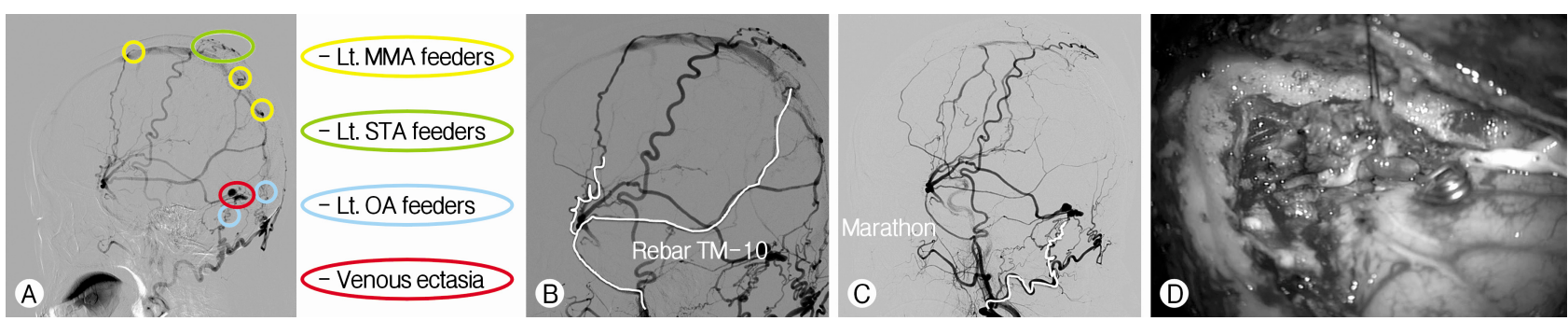

Fig. 2. (A) Stepwise treatment plan for the left (Lt.) middle meningeal arteries (MMA), Lt. superficial temporal artery, Lt. occipital artery (OA) and the venous ectasia. (B) Angiography during Onyx embolization of the Lt. MMA anterior and posterior branches using the Rebar microcatheter. (C) Angiography during Onyx embolization of the Lt. OA using the Marathon catheter platform. (D) Operation view of the venous ectasia clipping under general anesthesia using navigation. STA: superficial temporal artery. 

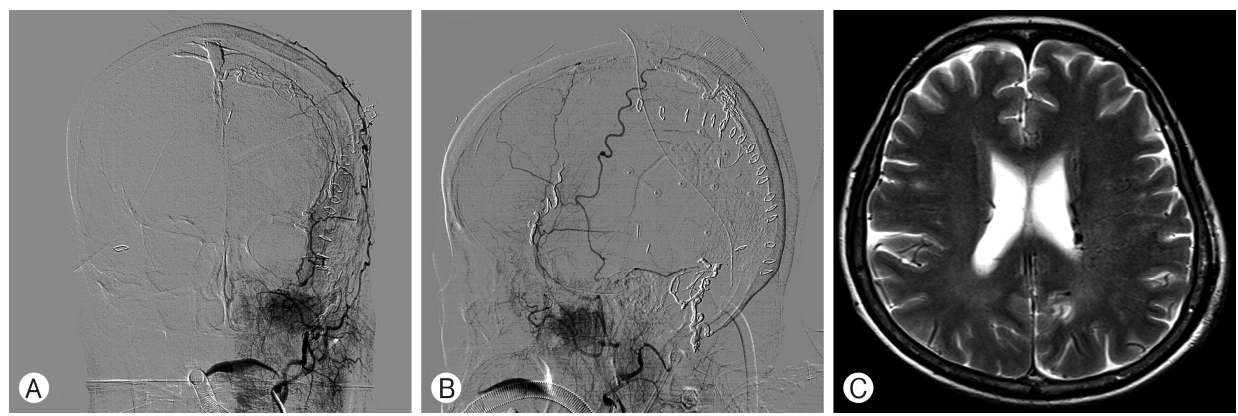

Fig. 3. Post-operation transfemoral cerebral angiography showing the disappearance of the feeding arteries the middle meningeal arteries, superficial temporal arteries, occipital arteries and the venous ectasia in the left external carotid artery. (A) Coronal view, (B) sagittal view. (C) Follow-up T2-weighted magnetic resonance image of the brain 20 days after the surgery, showing a prominent decrease in engorged vessels in both hemispheres.

hage along with a decrease in cognitive functions s. $^{3,6-12,14,16,17)}$.

The patient evaluated in this study was thought to have schizophrenia and was under treatment with psychiatric medication for 11 years. Although we searched the medical and scientific literature for any cases of dural AVFs accompanied by schizophrenia symptoms, no such case was found.

Initial TFCA revealed that the patient in this case had multiple dural AVFs, which are extremely rare and have a high probability of a malignant outcome. Therefore, aggressive treatment modalities are recommended for the clinical management of multiple dural AVFs ${ }^{4)}$.

Typically, the classification of dural AVF is determined by the venous drainage pattern, which determines the severity of the condition. There are two classification schemes, based on the Borden and Cognard system. In the present case, the dural AVF was drained from the MMA to the cortical vein with venous ectasia, which is classified as Borden type 3 and Cognard type $4^{2,3)}$.

In this case, the feeder arteries of the left ECA were thought to be the main feeder arteries; consequently, we planned a staged and aggressive treatment. During the intervention, starting with the first Onyx embolization, the previously prescribed anti-schizophrenia medication was stopped and the patient's schizophrenia symptoms worsened; these were brought under control only after the patient restarted the psychiatric medication.

However, after completion of the Onyx embolization along with the surgical ligation and clipping of the venous ectasia, the patient's symptoms of schizophrenia were markedly improved. Although she had stopped taking the psychiatric medication, she could express herself logically, could express her emotions precisely, and her delusions also disappeared.

It is possible that the patient could have been misdiagnosed with schizophrenia, although she showed decreased cognitive function when she first arrived at our hospital. Another possibility is that the improved cerebral blood flow after treatment had a significant effect on her schizophrenia symptoms.

\section{CONCLUSION}

Here, we reported a case of multiple dural AVFs presenting with schizophrenia symptoms. In this case, we used a staged and aggressive treatment that was effective in treating the condition and achieved significant improvement of associated symptoms. Brain MRI can be helpful in making an accurate diagnosis in cases where decreased cognitive functions or mental illness are present. We suggest that multiple dural AVFs should be actively treated in order to improve the symptoms.

\section{CONFLICTS OF INTEREST}

No potential conflict of interest relevant to this article was reported.

\section{REFERENCES}

1. Barnwell SL, Halbach VV, Dowd CF, Higashida RT, Hieshima GB, Wilson CB: Multiple dural arteriovenous fistulas of the cranium and spine. AJNR Am J Neuroradiol 12:441-445, 1991

2. Borden JA, Wu JK, Shucart WA: A proposed classification for spinal and cranial dural arteriovenous fistulous malformations and implications for treatment. J Neurosurg 82:166-179, 1995

3. Cognard C, Gobin YP, Pierot L, Bailly AL, Houdart E, Casasco A, et al.: Cerebral dural arteriovenous fistulas: clinical and angiographic correlation with a revised classification of venous drainage. Radiology 194:671-680, 1995

4. Guo Y, Yu J, Zhao Y, Yu J: Progress in research on intracranial multiple dural arteriovenous fistulas. Biomed Rep 8:17-25, 2018

5. Ha SY, Kwon YS, Kim BM, Kim DI, Kim DJ: Clinical and angiographic characteristics of multiple dural arteriovenous shunts. AJNR Am J Neuroradiol 33:1691-1695, 2012

6. Hasumi T, Fukushima T, Haisa T, Yonemitsu T, Waragai M: Focal dural arteriovenous fistula (DAVF) presenting with progressive cognitive impairment including amnesia and alexia. Intern 
Med 46:1317-1320, 2007

7. Hirono N, Yamadori A, Komiyama M: Dural arteriovenous fistula: a cause of hypoperfusion-induced intellectual impairment. Eur Neurol 33:5-8, 1993

8. Houser OW, Baker HL, Jr., Rhoton AL, Jr., Okazaki H: Intracranial dural arteriovenous malformations. Radiology 105:5564, 1972

9. Hurst RW, Bagley LJ, Galetta S, Glosser G, Lieberman AP, Trojanowski J, et al.: Dementia resulting from dural arteriovenous fistulas: the pathologic findings of venous hypertensive encephalopathy. AJNR Am J Neuroradiol 19:1267-1273, 1998

10. Iwata A, Nakamura K, Nukina N, Kanazawa I, Iwata M: A case of dural arteriovenous fistula accompanied by sinus occlusion. A serial study with CT scan. Rinsho Shinkeigaku 38:133137, 1998

11. Lee PH, Lee JS, Shin DH, Kim BM, Huh K: Parkinsonism as an initial manifestation of dural arteriovenous fistula. Eur J Neurol 12:403-406, 2005

12. Matsuda S, Waragai M, Shinotoh H, Takahashi N, Takagi K,
Hattori T: Intracranial dural arteriovenous fistula (DAVF) presenting progressive dementia and parkinsonism. J Neurol Sci 165:43-47, 1999

13. Newton TH, Cronqvist S: Involvement of dural arteries in intracranial arteriovenous malformations. Radiology 93:1071-1078, 1969

14. Obrador S, Soto M, Silvela J: Clinical syndromes of arteriovenous malformations of the transverse-sigmoid sinus. J Neurol Neurosurg Psychiatry 38:436-451, 1975

15. van Dijk JM, TerBrugge KG, Willinsky RA, Wallace MC: Multiplicity of dural arteriovenous fistulas. J Neurosurg 96:76-78, 2002

16. Waragai M, Takeuchi H, Fukushima T, Haisa T, Yonemitsu T: MRI and SPECT studies of dural arteriovenous fistulas presenting as pure progressive dementia with leukoencephalopathy: a cause of treatable dementia. Eur J Neurol 13:754-759, 2006

17. Yamakami I, Kobayashi E, Yamaura A: Diffuse white matter changes caused by dural arteriovenous fistula. J Clin Neurosci 8:471-475, 2001 